\title{
INFLUENCE OF LOW INTENSITY LASER BIOMODULATION ON THE OSSEOINTEGRATION OF DELAYED AND DELAYED-IMMEDIATE IMPLANTS
}

\author{
Tarek Abdel-Hamid Harhash*
}

\begin{abstract}
The aim of this study was to compare and contrast the influence of low-level laser therapy (LLLT) on the osseointegration of delayed and delayed-immediate dental implants. Forty implants were installed in the maxillary premolar regions of forty male subjects of age ranged 40-45 years old. Subjects were then randomly divided into four groups (I, II, III, and IV), delayed implant control group, delayed implant laser group, delayed-immediate implant control group, and delayedimmediate implant control group. Following implant insertion, the healing phase of groups (I and III) was left to progress spontaneously. Groups (II and IV) were subjected to low intensity (gallium arsenide diode) laser application with wavelength of $904 \mathrm{~nm}$, an output power of $30 \mathrm{mWatts}$, and a frequency of $9999 \mathrm{~Hz}$ for 3 minutes in three sessions on three alternative days starting from the tenth post-operative day. A six month follow up period was applied radiographically to all subjects of both groups using sequential conventional radiographs. Radiographs were digitized by a professional scanner and bone density was recorded. The results revealed that low intensity laser therapy (LLLT) provided an easy as well as efficient method for accelerating bone healing and improving osseointegration whatever the technique used for implant insertion. The study concluded that laser could be used as additional aid for improving osseointgration and increasing the success rate for implantation protocols.
\end{abstract}

KEYWORDS: Laser, LLLT, Osseointegration, Dental Implant.

\section{INTRODUCTION}

In implant dentistry, osseointegration phenomenon has become the accepted measurement for success or failure in dental implants. Yet, failure of dental implants accompanied by impaired healing, infection, and overload are still well recognized. ${ }^{(1)}$
Osseointegration is defined as "continuing structural and functional coexistence, possibly in a symbiotic manner, between differentiated, adequately remodeled, biologic tissues and strictly defined and controlled synthetic components, providing lasting, specific clinical functions without initiating

* Asst. Professor of Laser Dental Applications, Department of Medical applications of Laser, National Institute for Laser Enhancement Sciences, Cairo University. 
rejection mechanisms". ${ }^{(2)}$ One of the requirements for inducing osseointegration is a stress-free healing period of 3-6 months using a 2-stage surgical procedure (delayed implantation). This is to create a healing environment at the bone-implant interface that would facilitate regeneration and osseointegration rather than fibrous tissue encapsulation. ${ }^{(3)} \mathrm{Un}$ fortunately, the mandibular 3-month and maxillary 6-month no-load healing periods may be inconvenient for certain patients ${ }^{(4,5)}$, discouraging them from seeking such treatment.

The shortcomings of delayed technique led to the development of the immediate implantation, which is a technique that entails implant placement immediately or short after tooth extraction. (6) Delayed-immediate implantation is a technique which entails delaying the fixture placement for 3 to 5 weeks following extraction in an attempt to offer some additional advantages for immediate implants and to overcome some of the shortcomings. ${ }^{(7)}$ An ample time is allowed for the host tissue to eliminate any residual infection, secure wound closure is ensured to allow any handling of the soft tissue and avoid any mucogingival flap advancement to alleviate the need for additional surgeries to correct the mucogingival discrepancies. ${ }^{(8,9)}$

It removes the delay period, which in turn reduces patient and chair time as well as related cost. Another major benefit is bone preservation and subsequent enhanced esthetics. A socket refills postextraction, but internal and external wall remodeling generates an overall loss in horizontal and vertical dimension, about $3 \mathrm{~mm}$ to $6 \mathrm{~mm}$ and $1 \mathrm{~mm}$ to $2 \mathrm{~mm}$, respectively. ${ }^{(10-12)}$

Nowadays, the researches concerning the effect of low-level laser therapy (LLLT) on wound healing and bone regeneration have become a focus of recent research.LLLT is based on the use of monochromatic light to induce tissue biomodulation with various biomodulatory effects have been reported on wound healing ${ }^{(13)}$ and collagen synthesis. ${ }^{(14)}$ Regarding bone healing, LLLT has been shown to modulate inflammation ${ }^{(15)}$, accelerate cell proliferation ${ }^{(16)}$ and enhance healing ${ }^{(17)}$. This is why the study was aimed to evaluate the effect of low-level laser (LLL) on the healing phase following endosteal dental implant insertion. The focus of this study is to compare and contrast the effect of LLL on the healing phase and the osseointegration of both delayed and delayedimmediate implantation techniques. The results will be used to study the effect of LIL on osseointegration that follows the immediate implantation technique.

\section{MATERIAL AND METHODS}

\section{Case Selection}

The study was performed on forty selected males of age of 40-45 years that were primarily diagnosed, either as having partially edentulous areas that require restoration or as having a tooth that necessitates extraction followed by restoration. The cases were selected from the dental out-patients of the medical center in the National Institute of Laser Enhanced Sciences (NILES) in Cairo University.

\section{Criteria of case selection}

Cases were selected based on the following general inclusion criteria:

- Cases were non-smokers.

- Cases were free from any acute or chronic systemic disorders.

- Cases were free from non-treated generalized progressive periodontitis.

- Cases were having a good oral hygiene or at least the ability to improve it.

- The neighboring teeth to the receptor site were free from any acute periapical pathology (tooth was non-sensitive to percussion).

- None of the cases received any medications for at least one month before the start of the study. 
- None of the cases received head and neck radiation at any time.

- All cases presented an adequate interest and cooperation.

Criteria for selection of delayed implant groups:

- Selected case must have had at least one missing upper premolar in either side of the upper jaw.

- The missing tooth or teeth were due to previous extractions, trauma, and aplasia but not due to pathologic changes in the receptor site (cysts, tumors, osteomyelitis, etc.).

- The loss of tooth in the receptor site must have occurred with no less than six months before conducting the study.

- Receptor site presented sufficient bone volume corresponded to the implant length and diameter.

Criteria for selection of delayed-immediate implant groups:

- Cases that require extraction to at least one upper premolar in either side of the upper jaw.

- Extraction of the tooth in the receptor site was due to excessive decay without purulence and beyond restoration, remaining root, fractured root, endodontic failure, retained deciduous tooth, or trauma not affecting the alveolar bone.

Any case that did not fulfill the previous criteria was excluded from the study. All the study cases were informed about the study and were subjected to thorough diagnostic procedures included detailed medical and dental histories, clinical examination, radiographic examination, laboratory investigations, and study cast formation.

\section{Case categorization}

The previous examinations and diagnostic procedures allowed the selection of forty males that matched the criteria of case selection. Delayed implant groups included twenty males. Each case in these groups received an implant (FRIADENT GmbH P.O. Box 7101 11. 68221 Mannheim/ Germany) in the place of a missing maxillary premolar. Subjects were then randomly divided into two groups (I and II), in which each group included ten cases.

\section{Group I (Delayed Implant Control Group):} was left to progress spontaneously without any interference.

Group II (Delayed Implant Laser Group): received low intensity laser in sessions during the healing phase that followed implant insertion.

Delayed-immediate implant groups included twenty males. Each case in these groups was subjected to atraumatic extraction to the tooth of interest followed by implant insertion in the same site after five weeks from extraction. Subjects were then randomly divided into two groups (III and IV), in which each group included ten cases.

\section{Group III (Delayed-Immediate Implant} Control Group): was left to progress spontaneously without any interference.

Group IV (Delayed-Immediate Implant Laser Group): received low intensity laser in sessions during the healing phase that followed implant insertion.

\section{Laser Application}

Laser was applied to cases of groups II and IV in three sessions on three alternative days started from the tenth post-operative day (after removal of the sutures). In each session, laser device (ORALIA Dental Products Ltd., Weiherstraße 20, D-78465 Konstanz-Dettingen/Germany) was pre-adjusted to deliver a laser beam with a wavelength of 904 $\mathrm{nm}$, an output power of $30 \mathrm{~mW}$, and a frequency of $9999 \mathrm{~Hz}$ for 3 minutes. Along the pre-adjusted time (3 minutes), each surface (i.e. buccal, occlusal, and palatal surfaces respectively) was allowed to receive the laser beam for one minute. Laser beam was delivered continuously from the tip of 
the applicator to hit the target surface while the tip was touching the tissues in a direction towards the implant site. During laser delivery, the tip was moving in a continuous slow clockwise motion to assure full exposure of the target area to laser beam.

\section{Fabrication of radiographic template}

The radiographic template is a device that maintains the relation between x-ray tube, object, and radiographic film in a fixed position, even if the object has been imaged at different times. Radiographic template was fabricated from selfcure acrylic resin on the study cast of the upper dentition. Acrylic was manipulated while it was in the doughy stage. It was applied on the edentulous area of the cast that represented the area of interest and allowed to fill it and extend anteriorly and posteriorly to involve the crowns of the adjacent teeth. A periapical film packet was inserted horizontally into the posterior bite block of XCP device (Rinn Corporation, 1212 Abott Drive, Elgin, Illinois, USA). The bite block was adjusted over the occlusal plane (that was covered by acrylic) while the film was centering the target area to be imaged and the entire horizontal length of bite block was utilized to position the film in the mid-palatal area. Another doughy acrylic mix was applied on the part of the previous acrylic that filled the edentulous area, and then the bite block was pressed on the doughy acrylic till it produced indentations on it. The acrylic was pressed into the holes on the side of the bite block to create a reproducible relation between the template and the bite block.

\section{Radiographic schedule}

The evaluation of the osseointegration was radiographically performed through sequential radiographs taken to all cases at predetermined time intervals. Following the surgery, all the subjects were asked to recall according to a predetermined schedule for imaging procedures. A baseline radiograph was taken immediately postoperatively, and then the next images were taken at intervals of fifteen days for the next six months. The outcome of this procedure was thirteen standardized and reproducible images for each subject.

\section{Film processing, image scanning and storing}

Each set of films which belonged to the same subject was processed individually to assure that they received the same conditions during image processing. The procedure was applied to all films according to the recommended manufacturer's instructions.

The resultant images were scanned by means of high resolution PC scanner. Images of each subject were stored in PC within an individual folder belonged to its corresponding subject.

\section{Digital Image processing and Bone Density Determination}

Image analysis was performed using IDRISI Kilimanjaro software (Clark Labs, Clark University, 950 Main Street, Worcester MA 01610-1477, USA) that facilitated image restoration for both radiometric and geometric image correction. Image restoration was followed by image enhancement which allowed for contrast adjustment to all images, in addition, image enhancement facilitated implant edge enhancement. This was followed by subtracting the implant image from the background image (image of the surrounding bone). Finally, the measurements of density were calibrated by quantifying image on 256 gray scales. Zero scale was given to totally black regions, $256^{\text {th }}$ scale for totally white regions, while the values in between represented the variable shades of gray.

IDRISI assessed density of the surrounding bone through dividing it into two zones (fig. 1). The first zone was located just adjacent to the implant image and presented the osseointegration zone (implantbone interface). The second zone was just adjacent to first zone and presented the bone surrounding the implant. 


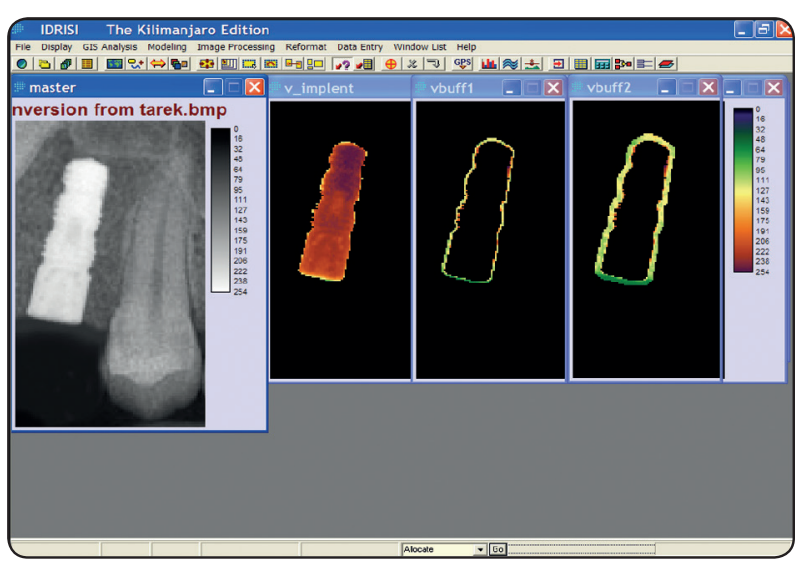

Fig. (1) Idrisi screen shows variable steps of the analytical procedure. From left to right: the image of the implant as it appears on Idrisi screen, the shade of the implant after manual determination of its boundaries, the first zone (osseointegration zone), and the second zone (surrounding bone).

\section{Statistical Analysis of Data}

All data were collected, tabulated, and statistically analyzed. Descriptive statistics as average, maximum values, minimum values, standard deviation, and mean percentage change were calculated for zones one and two in both groups.

\section{RESULTS}

The study was applied on forty cases; twenty cases presented the delayed implant groups that were randomly divided into two groups, the delayed implant control group (group I) and the delayed implant laser group (group II). The other twenty cases presented the delayed-immediate implant groups that were randomly divided into two groups, the delayed-immediate implant control group (group III) and the delayed-immediate implant laser group (group IV).

The resultant sequential radiographic images were subjected to densiometric studies using a software program that assessed density of the surrounding bone by dividing it into two zones (fig. 1). Zone I (ZI) that was just adjacent to the implant and presented an osseointegration zone (implant-bone interface), and zone II (ZII) that was just adjacent to the first zone and presented the surrounding bone.

Figures (2-a) and (2-b) show the bone density values of each two groups at zones I and II along the follow up period.

The difference between the baseline values at zones I and II in control groups (I and III) was high, so as to that of laser groups (II and IV) which necessitates data normalization to eliminate such differences. Figure (3) shows the normalized bone density values of different groups at zones I and II.

Data normalization revealed a positive difference between laser groups II and IV at both zones. The difference at zone I was to the favor of group II (delayed implant laser group) over the majority of the follow up intervals, and this difference diminished starting from the $10^{\text {th }}$ interval. The opposite appeared at zone II in which the difference was to the favor of group IV (delayed-immediate implant laser group) over the follow up intervals except for the $12^{\text {th }}$ where the values were nearly similar in both groups.

To clarify such a behavior, the percent of change in bone density was calculated at each follow up interval for zones I and II of laser groups II and IV as seen in figures (4-a) and (4-b).

Figure 4-a shows a progressive increase in the percent of change at zone I up to the third follow up interval for groups II and IV, and then the values maintained progressing but in a fluctuating manner along the rest of the intervals for both groups. There is an overall increase in values for both groups while the increase itself is fluctuating leading to a non-linear behavior. Zone I of group II was always attaining higher values compared to that of group IV except for the last two intervals.

Figure 4-b shows a progressive increase in percent of change values at zone II of both groups II 
and IV up to the third interval, and then the behavior became non-homogenous with irregular pattern in both groups till the end of the follow up intervals. Zone II in both groups attained smaller values of percent change than zone I of the same groups along the follow up period.

Both zones showed gradual increase in values up to the third interval where they possessed the highest values. Zone I possessed higher values compared to zone II values of both laser groups. The Highest values of zone II that occurred at the third interval was lower than that of zone I. The third interval recorded 39.95 for zone I and 35.45 for zone II of group II, while it recorded 25.96 for zone I and 24.88 for zone II of group IV.

Both, the non-homogeneity and the small values provided by zone II gave rise to a non-symmetrical relation between the behaviors at zones I and II of groups II and IV.

The statistical significance of the mean bone density among the pervious observations was achieved by applying t-Test (paired two sample for means) where $\mathrm{p} \leq 0.01$. The results are seen in table (1).

The results obtained from applying t-test on zone I of laser groups (II and IV) showed a significant difference in the favor of group IV concerning the mean bone density which indicated that the ability of laser in increasing the bone density was higher than in group II at zone I.

The results obtained from applying t-test on zone II of laser groups (II and IV) showed no significant difference between the two groups which may represent the diminished effect of laser that was overlapped by the irregular normal healing at this zone compared to zone I.

The results obtained from applying t-test on zone I of non-laser groups (I and III) showed a significant difference to the favor of group III concerning the mean bone density.

The results obtained from applying t-test on zone I of groups (I and II) showed a significant difference to the favor of group II concerning the mean bone density which indicated that the ability of laser in increasing the bone density was higher than normal healing in group I at zone I.

The results obtained from applying t-test on zone II of groups (I and II) showed a significant difference to the favor of group II concerning the mean bone density which indicated that the effect of laser was extended to affect zone II with an overall increase in density at higher level than that occurred at zone II of group I.

The results obtained from applying t-test on zone II of groups (III and IV) showed a significant difference to the favor of group IV concerning
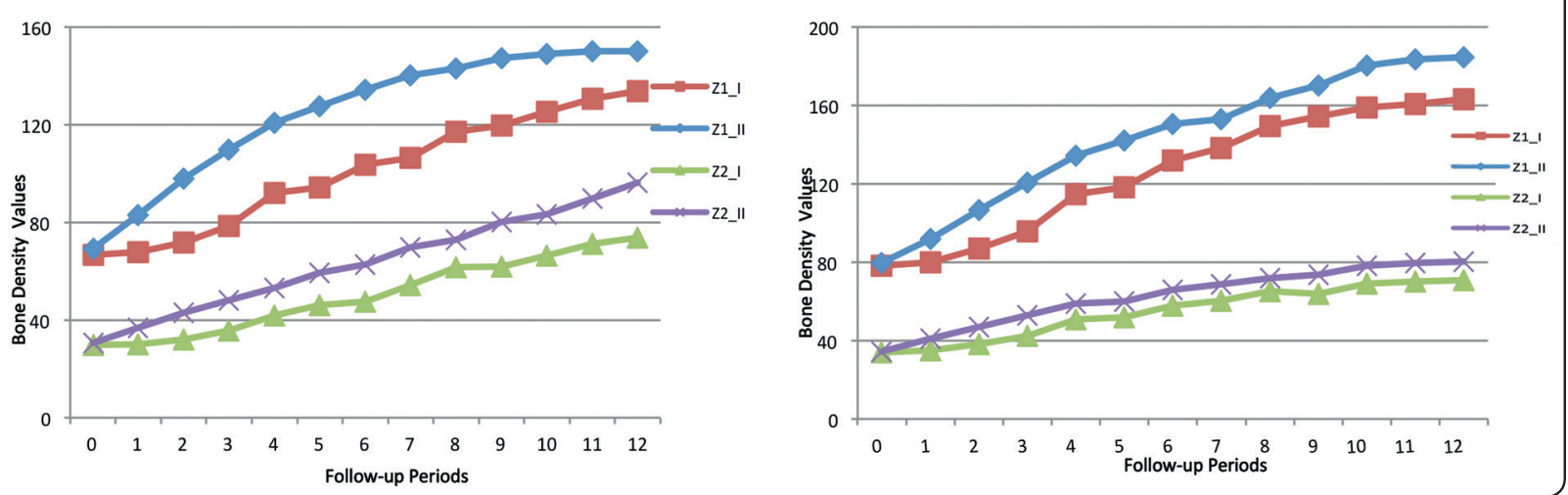

Fig. 2-a: Bone Density Values of Groups III \& IV at Zones I \& II (b) Bone Density Values of Groups III \& IV at Zones I \& II 


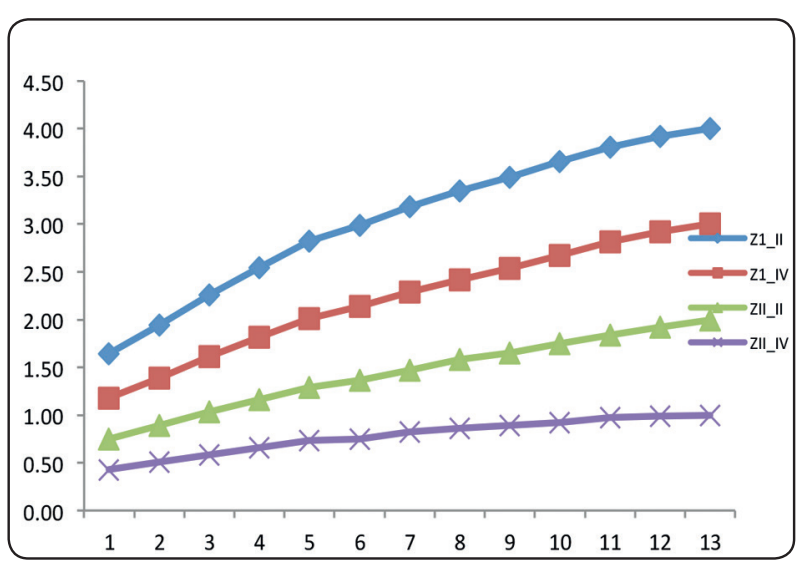

Fig. (3) Normalized Values of Bone Density at Zones I \& II of laser Groups II \& 4.50

the mean bone density which indicated that laser extended its effect to zone II with an overall increase in the bone density in a higher level than that resulted at zone II of group III.

Correlations between zones of selected groups were applied to study the degree of resemblance in the behaviors of such zones. Table (2) shows the results of these correlations. According to the correlation coefficient value for two correlated zones, the degree of resemblance between their behaviors could be estimated. The degree of resemblance is higher when the resultant correlation coefficient gets closer to the value of 1 . Accordingly, all the correlations in table (2) show high resemblance with variable degrees. The most interesting of such correlations are those of laser groups (II and IV).
The coefficient between zones I and II of group II was 0.944 , while the coefficient between zones I and II of group IV was 0.998. This means that the degree of resemblance in the behavior at zones I and II of group IV is higher than that of group II. Although zone I in group IV provided higher values for bone density compared to the values provided by zone II of the same group, but the behaviors at both zones possessed high resemblance. This was not the situation in group II that provided lesser resemblance in the behaviors of its zones. In other words, the effect of laser on group II was more obvious than on group IV although group IV provided higher difference in the values of bone density between zones I and II compared to that of group II.

The wound volume in group IV is greater than that of group II as it is formed of the wound resulted from the tooth extraction in addition to the surgical wound made by bone drilling while the wound in group II represents the surgical wound only. Zone II in group IV represents a part of the extraction wound that shows a progressive normal healing that was modified later by laser effect, while zone II in group II represents a relatively normal bone. Both laser effect and normal healing overlapped and intermingled with each other. This was not the situation in group II that provided lesser resemblance in the behaviors of its zones leading to a greater and more obvious laser effect.

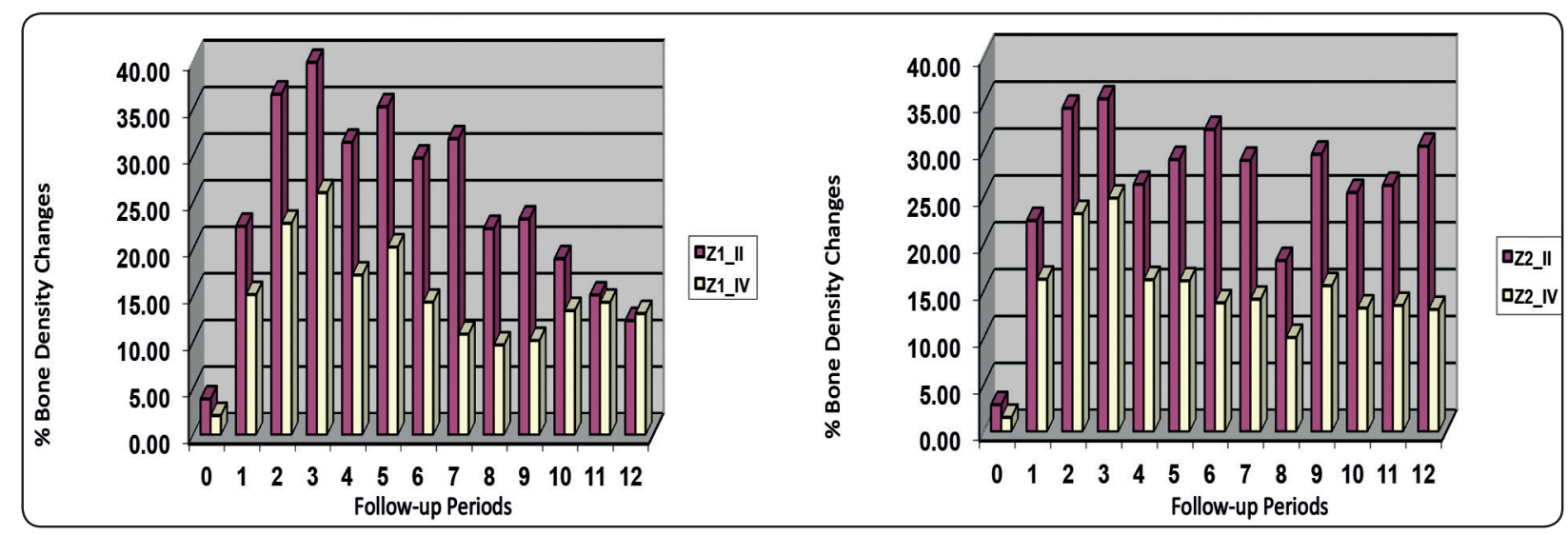

Fig. 4 (b) Percent of Change In Bone Density at Zone II of Groups II\&IV. (a) Percent of Change In Bone Density at Zone I of Groups II\&IV. 
Table 1. t-Test: Paired Two Sample for Means

\begin{tabular}{|c|c|c|c|c|c|}
\hline \multirow{5}{*}{ t-Test } & No & Groups & \multicolumn{2}{|c|}{ P-value } & Significance \\
\cline { 2 - 6 } & 1 & Z1_II \& Z1_IV & 0.000016 & $<0.01$ & Sign \\
& 2 & Z2_II \&Z2_IV & 0.55 & $>0.01$ & Non-Sign \\
& 3 & Z1_I \& Z1_III & 1.623 & $<0.01$ & Sign \\
\cline { 2 - 6 } & 4 & Z1_I \&Z1_II & 7.120 & $<0.01$ & Sign \\
\cline { 2 - 6 } & 5 & Z2_I \& Z2_II & 0.000002 & $<0.01$ & Sign \\
& 6 & Z2_III \& Z2_IV & 1.17 & $<0.01$ & Sign \\
\hline
\end{tabular}

\section{DISCUSSION}

Osseointegration resembles the primary bone healing process, in which an inflammatory process follows surgical trauma with a mediator cascade that promotes hematoma and circulatory alteration. This is followed by regeneration with replacement of the wound by bone tissue. Subsequently, bone remodeling which is influenced by occlusion pressure takes place leading to wound maturation. ${ }^{(18)} \mathrm{An}$ adequate regeneration results in direct contact between the implant surface and bone tissue (osseointegration). Implant failure occurs when a connective tissue capsule involves the implant instead of bone as a consequence of a repair process instead of regeneration resulting in a soft tissue capsule that surrounds the implant and promotes its mobility which is characteristic for early implant failure. ${ }^{(18,19)}$

Within the last decades, many experiments were conducted on implant treatment protocol in order to shorten the treatment period and to reduce the number of surgical procedures. One-stage surgical technique was one of the techniques that have been investigated. (20-24) This technique indicates the implant penetration of the mucosa during healing (transmucosal implant). Henceforth two options exist, either to wait a definite time before implant loading, or to load the implant immediately after positioning. Also, time between tooth extraction and implant insertion can be reduced by inserting the implant before complete healing of the extraction socket or inserting the implant immediately after the
Table 2. Correlation Coefficient Between Selected Groups

\begin{tabular}{|c|c|c|c|}
\cline { 2 - 4 } \multicolumn{1}{c|}{} & No & Groups & Correlation Coefficient \\
\hline \multirow{5}{*}{ Correlation } & 1 & Z1_II \& Z1_IV & 0.986 \\
\cline { 2 - 4 } & 2 & Z2_II \& Z2_IV & 0.979 \\
& 3 & Z2_I \& Z2__I & 0.944 \\
& 4 & Z2_III \& Z2_IV & 0.989 \\
& 5 & Z1_II \& Z2_II & 0.944 \\
& 6 & Z1_IV \& Z2_IV & 0.998 \\
\hline
\end{tabular}

tooth extraction thus, achieving the goal of inserting the implant immediately after tooth extraction and placing the prosthetic restoration on the same day of implant surgery. This concept has become a realistic replacement to the conventional approach both in association with single-tooth implants ${ }^{(25)}$ as well as multiple implant restorations ${ }^{(26)}$; however, the comparative prognoses between the conventional protocol and this "immediate" approach is still have little clinical evidence. ${ }^{(27)}$

This study was aimed at accelerating and/or improving osseointegration during the stress-free healing period that followed the insertion of the root analog by the 2 -stage surgical procedure.

Bone quality and quantity influence osseointegration and therefore the success of an implant. Bone quality has been suggested as an important prognostic indicator of dental implant success. ${ }^{(28)}$ In general, bone quality and quantity are superior in the mandible; hence, implant success is greater in the mandible as compared to the maxilla ${ }^{(29)}$, therefore the maxillary premolar region was used in this study as a standard implant placement site as this region is known to have lower bone quality (types III and IV) and higher failure rate compared to anterior region. Selecting maxillary premolar region as a standard region for the study provided an additional challenge against the attempts to improve and/or accelerate osseointegration by the studied methods.

This study was performed on male groups ranged from 40 to 45 years old. This range of age provided 
a sufficient availability of subjects with missed maxillary premolars due to trauma, extensive caries, or endodontic failure. This range was far from the range of active growth. ${ }^{(30,31)}$ In addition, this range provided a comparatively normal healing away from the delayed healing that might have occurred in the older age groups. Males were preferably used in this study instead of females to exclude any impact of female hormonal variations on the healing status. ${ }^{(32)}$ Thorough medical and dental histories, clinical examinations, radiographic evaluation, and laboratory investigations were applied on each subject before the study in order to exclude any systemic manifestations that could interfere with healing. Also, subjects with habits as smoking (33) and/or parafunctions (clenching and bruxism) ${ }^{(34)}$ were omitted from this study.

The influence of LLLT on wound healing and bone regeneration has become a focus of recent research. LLLT is based on biomodulation of the tissues with monochromatic light. Various biomodulatory effects have been reported on wound healing and collagen synthesis. ${ }^{(14)}$ With respect to bone, LLLT has been shown to modulate inflammation ${ }^{(15)}$, accelerate cell proliferation ${ }^{(16)}$ and enhance healing. ${ }^{(17)}$

Nicola et al., examined the activity in bone cells after application of LLLT close to the site of the bone injury and concluded that LLLT increases the activity in bone cells and remodeling process (resorption and formation) around the repair site without changing the bone architecture. ${ }^{(35)}$

Khadra et al., evidenced in a cellular model that LLLT enhanced the adhesiveness and multiplication of human mandibular bone cells cultured on titanium implant material. Exposure to laser with energy density of $3 \mathrm{~J} / \mathrm{cm}^{2}$ significantly enhanced osteocalcin and TGF-b1 production, which suggested the stimulation of osteoblast-like cells differentiation in a dose-dependent fashion. The authors concluded that LLLT is able to modulate the activity of cells and tissues surrounding an implant.
They also concluded that LLLT improves the functional attachment of titanium implants to bone and promotes bone healing and mineralization. ${ }^{(17)}$

Radwan D., proved in an in vivo study that LILT significantly enhanced bone density around delayed immediate titanium implants. Laser was delivered to subjects of laser group immediately after implant insertion surgery. They used laser parameters of $904 \mathrm{~nm}$ as a wave length, $30 \mathrm{~mW}$ as an output power, and a frequency of $9999 \mathrm{~Hz}$. in a continuous mode for 3 minutes. Using densiometric analysis, they concluded that laser irradiation significantly improved bone density around implants. ${ }^{(36)}$

Regarding the optimal recommended laser parameters used in the study, the usual ranges are from 0.5 to $10 \mathrm{~J} / \mathrm{cm}^{2}$. In general, laser wavelengths of 600 to $984 \mathrm{~nm}$ are used in physical medicine, and wavelengths of $632.8 \mathrm{~nm}$ helium neon and $904 \mathrm{~nm}$ GaAs are most frequently used in wound healing. ${ }^{(37.38)}$

Conventional radiography is a widely accepted technique for the long-term evaluation of changes in marginal bone at inter-proximal sites of implants. ${ }^{(39)}$

Digitization of conventional periapical images was used instead of direct digital radiography in accordance to Bhat et al. ${ }^{(40)}$ to gather the benefit of the high image resolution obtained by periapical films together with the benefits of digitization that included image enhancement, storage, and computer-assisted image analysis.

Follow up period extended for six months in accordance to Krennmair et al., ${ }^{(41)}$ who conducted a retrospective clinical analysis of 146 implants in a study on single tooth replacement with the FRIALIT-2 system and concluded that the six months healing period for the maxillary implants provided excellent results.

Baseline radiographs were taken immediately postoperatively. ${ }^{(28)}$ Recalls for follow up radiographs were made at intervals of two weeks for the six months period to allow for an accurate and a homogenous monitoring for any changes in bone 
density during the follow up period. The relatively low radiation parameters $(70 \mathrm{kVp}$ and $8 \mathrm{~mA}$ for $0.30 \mathrm{sec}$. using long cone and ultra-speed periapical films) allowed for such frequency of follow up radiographs.

Image analysis was performed using IDRISI Kilimanjaro software that facilitated image restoration, enhancement, and densiometric measurements.

IDRISI software facilitated monitoring the changes in bone density at two zones around implant images. The first zone represented the osseointegration zone and it was located just adjacent to the implant borders. The second zone was located just adjacent to first zone and represented bone around the implant. This software was chosen in accordance to Radwan (36) who was the first to use it in the dental researches after a pilot study to compare the software with $D I$ GORA software, in which IDRISI software proved to be easier and more accurate tool for densiometric analysis.

In the current study, low intensity laser was used as a regenerative approach to increase bone density and was proven to have positive results. Upon beginning the research work, there were differences in average baseline values of the four groups. This led to the performance of data normalization to eliminate such differences. Data normalization revealed a positive difference between laser groups II and IV at both zones. The difference at zone I was to the favor of group II over the majority of the follow up intervals. The opposite appeared at zone II in which the difference was to the favor of group IV over the majority of the follow up intervals.

Regarding the results of the calculated percent changes in bone density, both zones of laser groups (II and IV) showed gradual increase in values up to the third interval where they possessed the highest values. Zone I possessed higher values compared to zone II values of both laser groups. The Highest values of zone II that occurred at the third interval was lower than that of zone I. The third interval recorded 39.95 for zone I and 35.45 for zone II of group II, while it recorded 25.96 for zone I and 24.88 for zone II of group IV respectively.

Both, the non-homogeneity and the small values provided by zone II gave rise to a non-symmetrical relation between the behaviors at zones I and II of groups II and IV. These findings go in agreement with Dörtbudak et al., ${ }^{(42,43)}$ and Nicola et al., ${ }^{(35)}$ who concluded that LLLT increases the activity in bone cells at early phases of bone healing around the site of the repair without changing the bone structure.

Radiographic densiometric evaluation of osseointegration zone I revealed early sustained and homogenous increase in bone density in laser groups (II and IV). This finding was not observed in control groups (I and III). These findings go in agreement with Radwan ${ }^{(36)}$ who found that LLLT has accelerated bone formation around dental implants and this was evident from the first month of the follow up-periods.

Moreover, the observed increase in the osteoblastic activity in the first six weeks of laser therapy go in accordance with Ozawa et al., ${ }^{(44)}$ and Guzzardella et al., ${ }^{(45)}$ who observed an early significant increase in alkaline phosphatase activity after laser application, as well as early significant stimulated cellular proliferation and osteocalcin gene expression thereafter. Furthermore, laser irradiation at earlier stages significantly stimulated a greater number and larger area of bone nodules. Since alkaline phosphatase activity is an indication for bone cell maturation, and known to be associated with bone metabolism and differentiation of osteoblasts, hence, it is considered as one of the most frequently used parameters for osteoblastic differentiation and identification of osteogenic activity.

The magnitude of the biostimulatory laser effect depends on the physiologic state of the cell at the moment of irradiation. Variations in the magnitude of low-power laser effects at the cellular level are explained by the overall redox state $\left(\right.$ and $\mathrm{pH}_{\mathrm{i}}$ ) at the moment of irradiation. Cells with a lowered $\mathrm{pH}_{\mathrm{i}}$ (in which redox state is shifted to the reduced side) respond stronger than cells with a normal or 
close-to-normal $\mathrm{pH}_{\mathrm{i}}$ value. ${ }^{\left({ }^{(4)}\right)}$ This explains the high bone density values within laser groups along the follow up period compared to those of the control groups. It also explains the relatively higher change percentage of bone density in laser groups. During wound healing, laser biostimulates cells that present only in the proliferative phase or cells that are in a state of stress. ${ }^{(47)}$

The early significant increase in bone density in laser groups (the end of the first month) compared to control groups (the end of the second month) is supported by the results of Motomma et al., ${ }^{(48)}$ and Maegawa, et al., ${ }^{(49)}$ who observed an effect of LLLT on osseous tissue in promoting healing of bony wounds at the initial phase and an activity of accelerating osteogenesis. These findings are explained by Nicola and colleagues ${ }^{(35)}$ who demonstrated the positive effect of LLLT on the stimulation of bone with latent promotion of bone remodulation at injury sites without changes in bone architecture, increased bone volume and increased osteoblast surface through increased formation of bone with higher apposition rates.

Along the entire follow up period, there was a gap between laser and control groups. This gap was made by the relatively high difference in bone density values between laser and control groups along the follow up period to the favor of laser groups.

The effect of laser was evaluated by statistically comparing the mean bone density of different groups at different zones. The results showed a significant difference between laser groups (II and IV) and control groups (I and III) at both zones (I and II) to the favor of laser groups which indicated the ability of laser of increasing the bone density at both zones. These findings go in agreement with Radwan ${ }^{(36)}$ who reported that bone regeneration in their lased group was superior to the non-lased one. These results are explained by the studies of Nicola et al., ${ }^{(35)}$ Ueda and Shimizu; ${ }^{(50)}$ and Khadra et al., ${ }^{(51)}$ who found that LLLT accelerates cell proliferation, increases the activity of bone cells around the repair site without changing the bone structure, and processes faster bone maturation.
Laser induces angiogenesis, in which both blood and lymphatic capillaries undergo significant increase and regeneration in the presence of laser irradiation with a resultant improvement in circulation and perfusion enhances all repair and healing processes and facilitates absorption of the hematoma. ${ }^{(46,48,49,52)}$ Laser also stimulates vasodilation that enhances the transport of nutrients and oxygen to the damaged cells and facilitates repair and removal of cellular debris, adding to the reduction of ischemia and improved perfusion (Silveira, et al., ${ }^{(53)}$; Trelles, et al. ${ }^{(54)}$ Also, laser increases fibroblast proliferation, ${ }^{(55)}$ chondrocyte activity ${ }^{(44)}$, collagen production, ${ }^{(46)}$ bone remodeling from increased osteoblastic activity and deposition of calcium salts. ${ }^{(58)}$

Although the density in the second zone was less than its correspondence in the osseointegration zone, yet the density of the second zone in the laser groups (II and IV) showed a significant increase than control groups (I and III), i.e. laser therapy provided faster osseous tissue formation and enhanced bone vascularization. ${ }^{(44,52)}$

There was a statistically significant difference between group IV and group II at zone I to the favor of group IV which denotes a higher laser effect in this group at zone I. No statistical difference occurred by comparing the results of the same groups at zone II.

In fact, there is a great difference in the state of the tissue presented by each zone. Zone I in all groups presented the bone that was in direct contact with the implant surface and it was made by surgical drilling into a healthy bone (formed by minimal bone irritation and filled by the implant that reduced the wound volume) in delayed implant groups (I and II), while in delayed-immediate implant groups (III and IV), the surgical wound was made in an already healing area from the previous tooth extraction. Also, zone II was different in these groups. This zone in delayed implant groups presented a relatively healthy bone that acted as intermediary zone for the inflammatory processes that served 
the healing and osseointegration in zone I, while zone II of delayed-immediate implant groups was part of the progressively healing socket and was already passed a stage of the regeneration process. This was the case at the time of laser application on laser groups (II and IV). Laser application produced its effect on the outcome of two wounds at zone I of group IV compared to the single surgical wound at zone I in group II and this was translated to a higher laser effect in group IV at this zone. On the other hand, the laser effect on the relatively older wound that was resulted from the extraction at zone II of group IV was less obvious as it was overlapped by the irregular behavior of the progressive normal healing, thus, no significant difference appeared between zone II of group IV and zone II of group II that presented a relatively normal bone with low laser effect on it.

The correlation between the statistical analyses of radiographic bone density in the two bone zones that surrounded the implants assured that laser accelerated healing and osteogenesis when compared to control groups, the findings go in accordance with the results of Radwan, ${ }^{(36)}$ Salah ElDin and Dahaba, ${ }^{(59)}$ and Salah El-Din et al, ${ }^{(60)}$ who found an increase in the percentage of bone density in their laser groups compared to non-lased groups. The correlation findings of groups II and IV at zones I and II showed that the effect of laser on group II was more obvious than on group IV although it provided high difference in values for bone density between zones I and II compared to that of group II. Also, group II attained the highest percent of changes in bone density regarding both zones except for the $12^{\text {th }}$ interval in group IV at zone I.

The results of the current clinical study denoted that low intensity laser therapy provides an easy as well as efficient method for accelerating bone healing and improves osseointegration whatever the technique used for implant insertion. Laser could be used as additional aid for improving osteointegration and increasing the success rate for implantation procedures.

\section{REFFERENCES}

1. Ratner, B.D. (2001): Replacing and Renewing: Synthetic Materials, Biomimetics, and Tissue Engineering in Implant Dentistry. Journal of Dental Education; 65(12): 1340-1347.

2. Brånemark, R., Brånemark, P-I., Rydevik, B., Myers, R.R. (2001): Osseointegration in skeletal reconstruction and rehabilitation: A review. J Rehabil Res Dev; 38: 175-181.

3. Brånemark, P-I., Hansson, B. O., Adell, R., et al. (1977): Osseointegrated implants in the treatment of the edentulous jaw. Experience from a 10-year period. Scand J Plast Reconstr Surg; 16: 1-132.

4. Balshi, T. J., Wolfinger, G. J. (1997): Immediate loading of Brånemark implants in edentulous mandibles: A preliminary report. Implant Dentistry; 6: 83-88.

5. Tarnow, D. P., Emtiaz, S., Classi, A. (1997): Immediate loading of threaded implants at stage 1 surgery in edentulous arches: Ten consecutive case reports with 1- to 5- year data. Int J Oral Maxillofac Implants; 12: 319-324.

6. Adell R, Eriksson B, Lekholm U, Brånemark PI, Jemt T. (1990): A long-term follow-up study of osseointegrated implants in the treatment of totally edentulous jaws. Int $\mathbf{J}$ Oral Maxillofac Implants; 5:347-59.

7. Wilson, J. and Weber, D. (1993): Tissue response to bioglass endosseous ridge maintenance implants. J Oral Implantol; 19:295-302.

8. Parodi, R.; Santarelli, G.; and Carusi, G. (1996): Application of slow resorbing collagen membrane to periodontal and peri-implant guided tissue regeneration. Int J Periodontics Restorative Dent; 16(2):174-181.

9. Spiekermann, H.; Donath, T.; Hassell, S.; Jovanovic, and Richer, J (1995): Color atlas of dental medicineimplantology. George Thieme Verlag, Stuttgart, New York.

10. Camargo, P.M.; Lekovic, V.; Weinlaender, M.; et al. (2000): Influence of bioactive glass on changes in alveolar process dimensions after exodontia. Oral Surg Oral Med Oral Pathol Oral Radiol Endod; 90:581-586.

11. Iasella, J.M.; Greenwell, H.; Miller, R.L.; et al. (2003): Ridge preservation with freeze-dried bone allograft and a collagen membrane compared to extraction alone for implant site development: a clinical and histologic study in humans. J Periodontol; 74:990-999.

12. Lekovic, V.; Camargo, P.M.; Klokkevold, P.R.; et al. (1998): Preservation of alveolar bone in extraction sockets using bioabsorbable membranes. J Periodontol; 69:10441049 . 
13. García-Morales, J.M., Tortamano-Neto, P., Marotti, J.; et al. (2012): Stability of dental implants after irradiation with an 830-nm low-level laser: a double-blind randomized clinical study. Lasers Med Sci; 27:703-711

14. Trelles, M.A., Mayayo, E. (1987): Bone fracture consolidates faster with low-power laser. Lasers Surg Med; 7: 36-45.

15. Ghamsari, S.M., Yamada, H., Acorda, J.A., Taguchi, K., Abe, N. (1995): Histopathological effects of low-level laser therapy on secondary wound healing of teat wound in dairy cattle. Laser Ther; 7: 81-8.

16. Lizarelli, R.F.Z., Lamano-Carvalho, T.L., Brentegani, L.G. (1999): Histometrical evaluation of the healing of the dental alveolus in rats after irradiation with a low-powered GaAlAs laser. SPIE; 3593: 49-55.

17. Ueda, Y., Shimizu, N. (2003): Effects of pulse frequency of low-level laser therapy (LLLT) on bone nodule formation in rat calvarial cells. J Clin Laser Med Surg; 21: 271-7.

18. Khadra, M., Lyngstadaas, S. P., Hans, R., Haanæs, H. R., Mustafa, K. (2005): Effect of laser therapy on attachment, proliferation and differentiation of human osteoblast-like cells cultured on titanium implant material. Biomaterials; 26: 3503-3509.

19. Santos, M. C. L. G., Campos, M. I. G., Line, S. R. P. (2002): Early dental implant failure: A review of the literature. Braz J Oral Sci; 1(3): 103-111.

20. Elsubeihi, E.S., Zarb, G.A. (2002): Implant Prosthodontics in Medically Challenged Patients: The University of Toronto Experience. J Can Dent Assoc; 68(2): 103-8.

21. Schroeder A, van der Zypen E, Stich H, Sutter F. (1981): The reactions of bone, connective tissue, and epithelium to endosteal implants with titanium-sprayed surfaces. J Maxillofac Surg; 9:15-25.

22. Buser, D., Weber, H.P., Lang, N.P. (1990): Tissue integration of non-submerged implants. 1-year results of a prospective study with 100 ITI hollow-cylinder and hollowscrew implants. Clin Oral Implants Res; 1:33-40.

23. Buser, D., Weber, H.P., Bragger, U., Balsiger, C. (1991): Tissue integration of one-stage ITI implants: 3-year results of a longitudinal study with Hollow-Cylinder and HollowScrew implants. Int J Oral Maxillofac Implants; 6:405-12.

24. Buser, D., Mericske-Stern, R., Bernard, J.P., Behneke, A., Behneke, N., Hirt, H.P., et al. (1997): Longterm evaluation of non-submerged ITI implants. Part 1: 8-year life table analysis of a prospective multi-center study with $2359 \mathrm{im}-$ plants. Clin Oral Implants Res; 8:161-72.
25. Ericsson, I., Randow, K., Nilner, K., Petersson, A. (2000): Early functional loading of Brånemark dental implants: 5-year clinical follow-up study. Clin Implant Dent Relat Res; 2:70-7.

26. Chaushu, G., Chaushu, S., Tzohar, A., Dayan, D. (2001): Immediate loading of single-tooth implants: immediate versus non-immediate implantation. A clinical report. Int J Oral Maxillofac Implants; 16:267-72.

27. Brånemark, P-I., Engstrand, P., Ohrnell, L.O., Gröndahl, K., Nilsson, P., Hagberg, K., et al. (1999): Brånemark Novum: a new treatment concept for rehabilitation of the edentulous mandible. Preliminary results from a prospective clinical follow-up study. Clin Implant Dent Relat Res; 1:2-16.

28. Misch, C.E., Scortecci, G.M. (2015): Immediate load applications in implant dentistry. In Misch CE (ed): Dental implant prosthetics. St. Louis, Mosby-Year Book; pp 531-567.

29. Saadoun, A.P., Landsberg, C.J. (1997): Treatment classifications and sequencing for postextraction implant therapy: a review. Practical Periodontics \& Aesthetic Dent; 9:933-41.

30. Cochran, D.L. (1999): Endosseous dental implant surfaces in human clinical trials. A comparison using meta-analysis. J Periodontol; 70:1523-1539.

31. Beikler, T., Flemmig, T.F. (2003): Implants in the medically compromised patiant. Crit Rev Oral Biol Med ;14(4): 305-316.

32. Bryant, S.R. (1998): The effects of age, jaw site, and bone condition on oral implant outcomes. Int J Prosthodont; 11: 470-90.

33. Wood, M.R., Vermilyea, S.G. (2004): A review of selected dental literature on evidence-based treatment planning for dental implants: Report of the Committee on Research in Fixed Prosthodontics of the Academy of Fixed Prosthodontics. J Prosthet Dent; 92: 447-62.

34. Wilson, T.G. Jr., Nunn, M. (1999): The relationship between the interleukin-1 periodontal genotype and implant loss. Initial data. J Periodontol; 70: 724-9.

35. Nicola, R.A., Jorgetti, V., Rigau, J., Pacheco, M.T., dos Reis L.M., Zangaro, R.A. (2003): Effect of low-power GaAlAs laser $(660 \mathrm{~nm})$ on bone structure and cell activity: an experimental animal study. Lasers Med Sci; 18(2):89-94.

36. Radwan, D., A. (2005): A clinical study on the effect of diode laser therapy on the osseointegration of delayed immediate implants. A thesis of doctor's degree in oral surgery, Cairo University. 
37. Demir, H., Yaray, S., Kirnap, M., Yaray, K. (2004): Comparison of the effects of laser and ultrasound treatments on experimental wound healing in rats. JRRD; 41(5): 721-728.

38. Sousa, R.G., Batista, K.N.M. (2016): Laser therapy in wound healing associated with diabetes mellitus - Review. An Bras Dermatol; 91(4):489-93

39. Salvi, G.E., Lang, N.P. (2004): Diagnostic Parameters for Monitoring Peri-implant. Int J Oral Maxillofac Implants; 19(SUPPL):116-127.

40. Bhat, S., Shetty, S., Shenoy, K.K. (2005): Imaging in implantology. JIPS; 5(1):10-14.

41. Krennmair, G., Schmidinger, S., Waldenberger, O. (2002): Single-Tooth Replacement with the Frialit-2 System: A prospective Clinical Analysis of 146 Implants. Int J Oral Maxillofac Implants; 17(1):78-85.

42. Dörtbudak, O., Hass, R., Mallath-Pokorny, G. (2000): Biostimulation of bone marrow cells with a diode soft laser. Clin Oral Implants Res; 11(6): 540-5.

43. Dörtbudak, O., Haas, R., Mailath-Pokorny, G. (2002): Effect of low-power laser irradiation on bony implant sites. Clin Oral Implants Res; 13(3): 288-292.

44. Ozawa, Y., Shimizu, N., Mishima, H., Kariya, G., Yamaguchi, M., Takiguchi, H., Iwasawa, T., Abiko, Y. (1995): Stimulatory effects of low-power laser irradiation on bone formation in vitro. In Altshuler, G.B., Blankenau, R.J., Wifdor, H. A. (eds): Advanced laser Dentistry. SPIE; 1984, pp 281- 288.

45. Guzzardella, G.A., Torricelli, P., Nicoli-Aldini, N., Giardino, R. (2003): Osseointegration of endosseous ceramic implants after postoperative low-power laser stimulation: an in vivo comparative study. Clin Oral Implants Res; 14: 226-232.

46. Karu, T.I. (2003): Low-Power Laser Therapy. In: Biomedical Photonics Handbook. Boca Raton, CRC Press. pp 48-1--48-25.

47. Walker, D.M., Rumpf, S., Baxter, D.G., Lowe, S.A. (2000): Effect of low intensity laser irradiation (660 mm) on the radiation-impaired wound healing model in murine skin. Lasers Surg Med; 26:41-47.

48. Motomma, K., Nakashima, M., Ihara, A., Atsmi K. (1986): Effect of argon-dye laser on fracture healing. Journal of Japan society of laser medicine; 6(3): 171-174.

49. Maegawa, Y., Itoh, T., Hosokawa, T., Yaegashi, K., Nishi, M. (2000): Effects of Near-Infrared Low-Level Laser
Irradiation on Microcirculation. Lasers in surgery and medicine; 27: 427-437.

50. Ueda, Y., Shimizu, N. (2003): Effects of pulse frequency of low-level laser therapy (LLLT) on bone nodule formation in rat calvarial cells. J Clin Laser Med Surg; 21: 271-7.

51. Khadra, M., Lyngstadaas, S. P., Hans, R., Haanæs, H. R., Mustafa, K.(2005):Effect of laser therapy on attachment, proliferation and differentiation of human osteoblast-like cells cultured on titanium implant material. Biomaterials; 26: 3503-3509.

52. Gable, P., Tunér, J. (2003): Bone Stimulation by Low Level Laser - A Theoretical Model for the Effects. Clinixperience; Vol. 2003(67).

53. Silveira LB, et al. (2002): In vivo study on mast cells behavior following low-intensity visible and near infrared laser radiation. Laser Surg Med. Abstract issue. Abstract 304.

54. Trelles, M.A., et al. (2000): LLLT in vivo effects on mast cells. Department of Tissue Pathology, University Hospital, Tarragona, Spain. Abstract from the $7^{\text {th }}$ International Congress of European Medical Laser Association, Dubrovnik, Croatia, June 2000.

55. Almeida-Lopes, L., Rigau, J., Zângaro, R.A., GuidugliNeto, J., Jaeger, M.M.M. (2001): Comparison of the Low Level Laser Therapy Effects on Cultured Human Gingival Fibroblasts Proliferation Using Different Irradiance and Same Fluence. Lasers in Surgery and Medicine; 29:179184.

56. Karu, T.I., Pyatibrat, L.V., and Kalendo, G.S. (2001): Donors of NO and pulsed radiation at $1=820 \mathrm{~nm}$ exerts effects on cells attachment to extracellular matrices. Toxicol Lett; 121, 57.

57. Reddy, G. K., Stehno-Bittel, L., Enwemeka, C.S. (1998): Laser Photostimulation of Collagen Production in Healin Rabbit Achillis Tendons. Lasers in Surgery and Medicine; 22:281-287.

58. Karu, T.I. (2003): Low-Power Laser Therapy. In: Biomedical Photonics Handbook. Boca Raton, CRC Press. pp 48-1--48-25.

59. Salah El-Din, M., Dahaba, M.M. (2001): Effect of diode laser therapy on healing of persistent periradicular lesions in endodontically treated teeth. Egy Dent J; 47: 299-309.

60. Salah El-Din, M., Marzouk, A., Dahaba, M.M. (2004): The effect of low energy laser on endo-perio and periapical lesions. Egy Dent J; 50: 103-112. 